\title{
Progress on a Gas-Accepting Ion Source for Continuous-Flow Accelerator Mass Spectrometry
}

\author{
M.L. Roberts ${ }^{1)}$, R.J. Schneider ${ }^{1)}$, K.F. von Reden ${ }^{1)}$, J.S.C. Wills ${ }^{2)}$, B.X. Han ${ }^{1)}$, J.M. Hayes ${ }^{1)}$, B.E. \\ Rosenheim $^{1)}$, and Jenkins, W.J. ${ }^{1}{ }^{1}$ \\ 1) National Ocean Sciences AMS Facility, Department of Geology and Geophysics, Woods Hole Oceanographic \\ Institution, Woods Hole, MA 02543, USA. \\ 2) Atomic Energy of Canada Ltd., Chalk River Laboratories, Chalk River, ON, Canada K0J 1P0. \\ E-mail address of main author: mroberts@whoi.edu
}

\begin{abstract}
A gas-accepting microwave-plasma ion source is being developed for continuous-flow Accelerator Mass Spectrometry (AMS). Characteristics of the ion source will be presented. Schemes for connecting a gas or liquid chromatograph to the ion source will also be discussed.

\section{Introduction}

The National Ocean Sciences AMS (NOSAMS) facility at Woods Hole Oceanographic Institution is constructing a compact AMS system optimized for the analysis of ${ }^{14} \mathrm{C}$ in a continuously flowing gas stream. Because it will allow the continuous monitoring of chromatographic effluents, the new system will enable dramatic expansion of significant and well established lines of inquiry including: (i) surveys of the distribution of radiocarbon among natural products and thus of the sources of those materials ${ }^{[1]}$, (ii) quantitation of ${ }^{14} \mathrm{C}$ tracers at extraordinary levels of dilution, and (iii) recognition of fossil-fuel-derived pollutants in natural systems by exploiting their zero content of ${ }^{14} \mathrm{C}$ as a 'negative label ${ }^{\text {,2] }}$.

The key component of this new system will be a gas-accepting microwave-plasma source first built at Atomic Energy of Canada Limited, Chalk River, Ontario, Canada and subsequently developed at NOSAMS ${ }^{[3,4,5,6,7]}$. A schematic of the source is shown in Figure 1. The source uses $2.45 \mathrm{GHz}$ microwaves and continuously flowing gas feed to sustain a plasma. Positive ions are extracted from the source and converted to negative ions by passage through a magnesium-vapor charge-exchange canal located at the exit of the ion source.
\end{abstract}




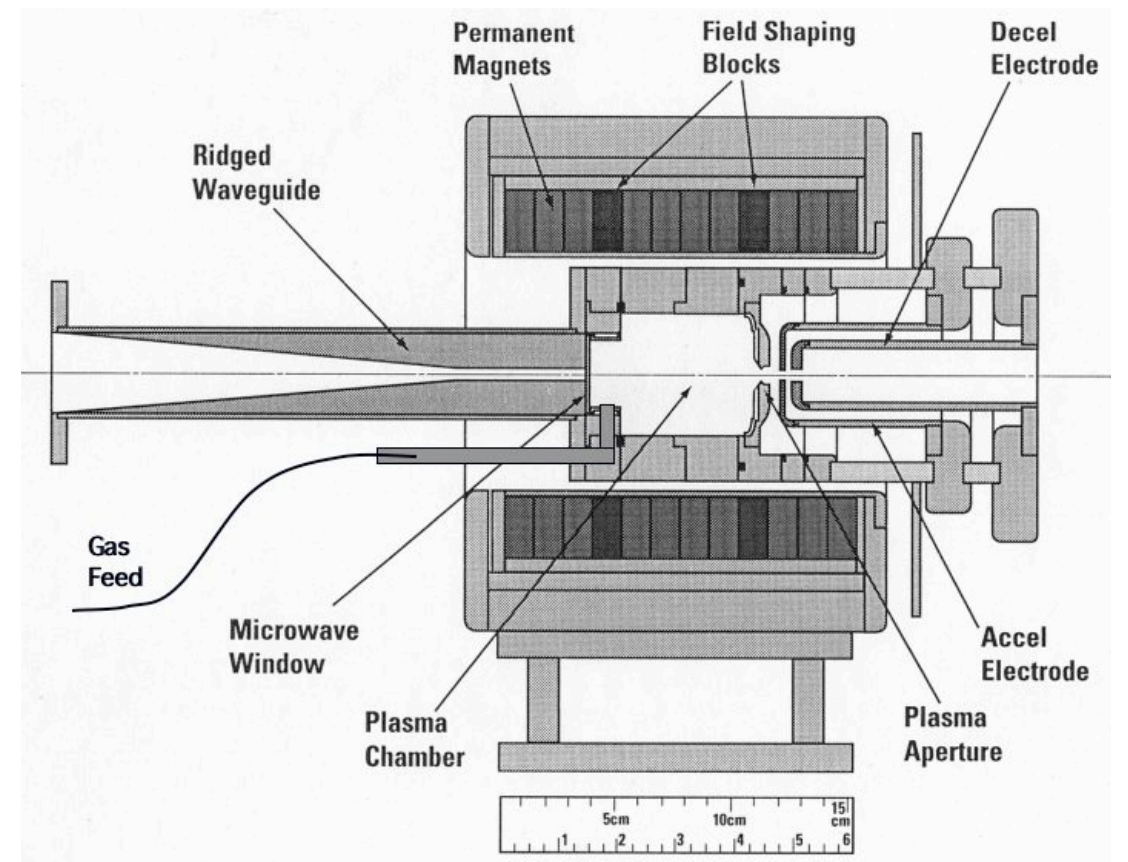

Figure 1. The AECL gas-accepting microwave-plasma ion source. In our case, the length of the plasma chamber was shortened from $5 \mathrm{~cm}$ as shown to $2.5 \mathrm{~cm}$ to reduce the volume.

\section{Performance of the Gas Ion Source}

For characterization, the gas ion source was mounted on an ion-source test stand. The arrangement, shown in Figure 2, consisted of a combustion system, a gas-transfer system, the ion source, the magnesium-vapor charge-exchange canal, a $90^{\circ}$ double-focusing magnet, two offaxis Faraday cups for the simultaneous measurement of mass-12 and mass-13 beams, and a rotating-wire beam-profile monitor. The double-focusing magnet had a $70 \mathrm{~mm}$ aperture with object and image points about $69 \mathrm{~cm}$ from the effective field boundary. This setup was useful in optimizing the gas-transfer system, the ion source, and charge-exchange canal. 


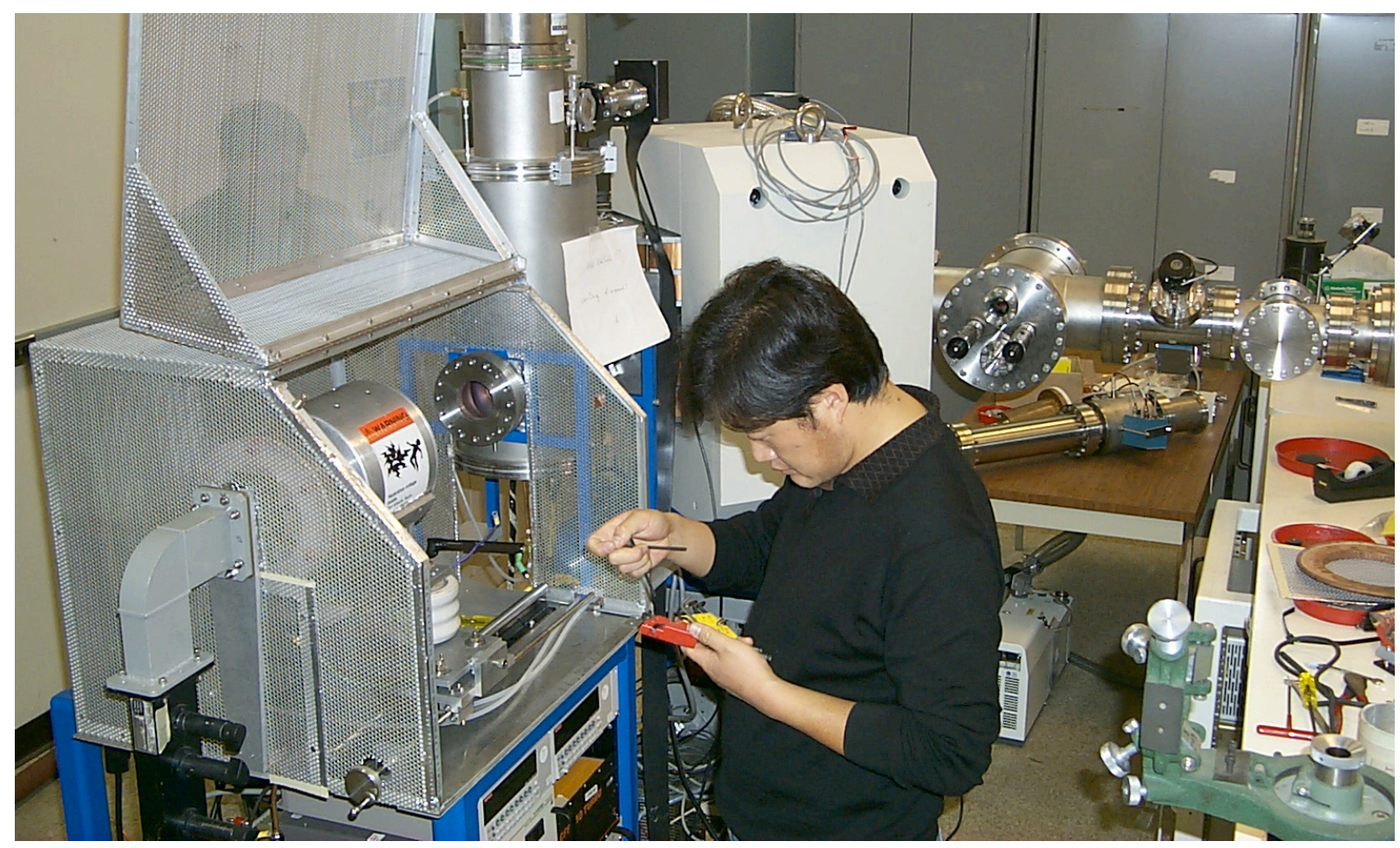

Figure 2. The ion source mounted on the ion-source test stand. The ion source is to the left inside the cage and the double focusing magnet is back center.

Gas flowed to the ion source via a 100-micron diameter, fused-silica capillary. By varying the length of the capillary, different gas flow rates could be selected. Maximum ionsource output of $\mathrm{C}^{+}$from $\mathrm{CO}_{2}$ gas was obtained with a capillary length of $2.2 \mathrm{~m}$ at an extraction voltage of $30 \mathrm{kV}$. At this length, the measured $\mathrm{CO}_{2}$ gas flow rate was $240 \mathrm{~L} / \mathrm{min}$, which agrees well with a calculated flow rate of $230 \mathrm{~L} / \mathrm{min}$ using Poiseuille's equation. The volume of the plasma discharge chamber is 40cc. The chamber is coupled to the external, turbo-pumped vacuum system through a $5 \mathrm{~mm}$ diameter extraction aperture. The starting, or base pressure, is about $2 \times 10^{-6} \mathrm{~T}$. The conductance through the $5 \mathrm{~mm}$ aperture is about $2 \mathrm{1} / \mathrm{s}$, but the gas flow introduced by the capillary results in a pressure differential across this boundary. As the static pressure builds up during gas flow, a discharge starts at about $10^{-5} \mathrm{~T}$, reaching a maximum about $3 \times 10^{-5} \mathrm{~T}$, as measured externally to the discharge chamber. The actual internal pressure of the plasma chamber is unknown.

Figure 3 shows a mass scan of emitted ion beams when pure $\mathrm{CO}_{2}$ was used as a feed gas. With the charge-exchange canal turned off, and using a flow rate of $240 \mu \mathrm{L} / \mathrm{min}, \mathrm{C}^{+}$ion currents of $400 \mu \mathrm{A}$ were obtained at an extraction voltage of $30 \mathrm{kV}$ and 125 watts of RF power. With the charge-exchange canal turned on, $\mathrm{C}^{-}$currents of $63 \mu \mathrm{A}$ were obtained. This implies an ion source and beam transport efficiency of $2.3 \%$ for the conversion of $\mathrm{CO}_{2}$ ions to $\mathrm{C}^{+}$ions, a chargeexchange canal efficiency of $15 \%$ for the conversion of $\mathrm{C}^{+}$ions to $\mathrm{C}^{-}$, and an overall efficiency of $0.4 \%$ for the conversion of $\mathrm{CO}_{2}$ ions to $\mathrm{C}^{-}$ions. 


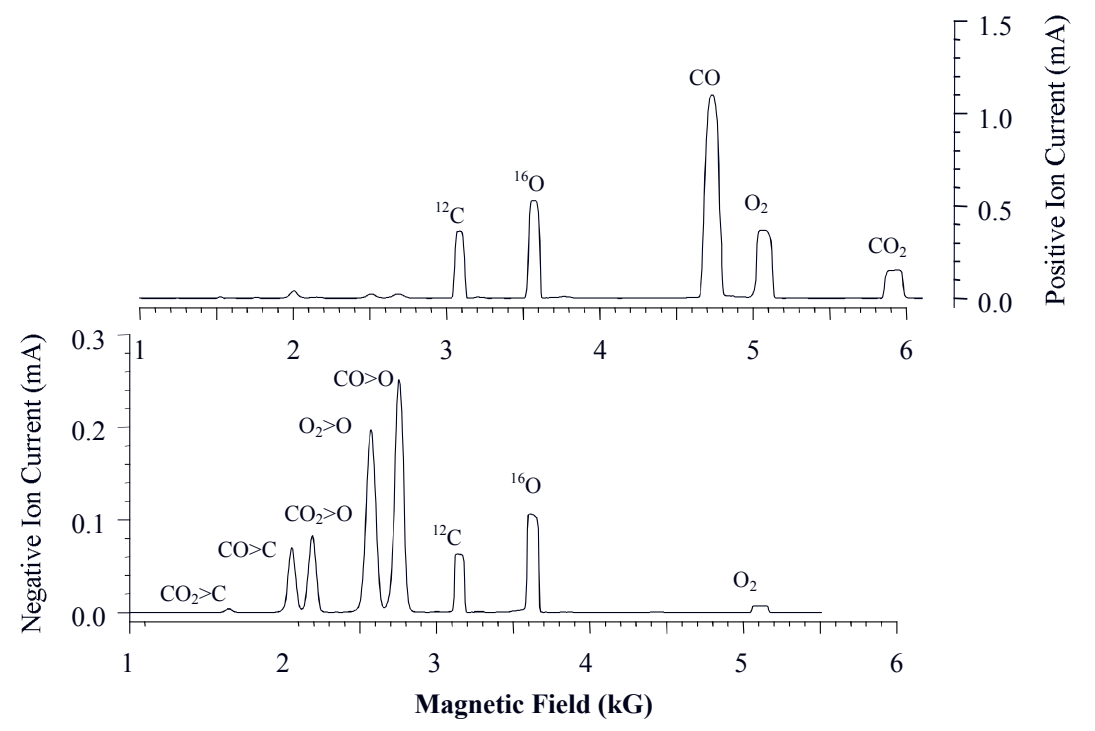

Figure 3. Mass scan using $\mathrm{CO}_{2}$ as a gas feed. The upper scan is with the charge-exchange canal turned off (positive ions) while the lower scan is with the charge-exchange canal turned on (negative ions). The extraction potential was $25 \mathrm{kV}$.

Divergence of the ion beam was measured by using a National Electrostatics Corporation (NEC) rotating-wire beam-profile monitor in a setup shown schematically in Figure 4. Using $\mathrm{CO}_{2}$ as a feed gas, a $30 \mathrm{keV}$ positive-ion beam was extracted from the $5 \mathrm{~mm}$ ion source aperture and passed through the $10-\mathrm{mm}$ diameter charge exchange canal. At $410 \mathrm{~mm}$ from the exit of the charge exchange canal, the negative-ion beam had a diameter of $23 \mathrm{~mm}$. This gives a divergence of approximately $16 \mathrm{mrad}$ and an approximate beam emittance of $80 \pi \cdot \mathrm{mm} \cdot \mathrm{mrad}$. This is significantly more than the emittance of a typical solid-sample cesium sputter-source $\left(8 \pi \cdot \mathrm{mm} \cdot \mathrm{mrad}\right.$ for the NEC SNICS source ${ }^{[8]}, 40 \pi \cdot \mathrm{mm} \cdot \mathrm{mrad}$ for the Lawrence Livermore National Laboratory sputter source ${ }^{[9]}$ ). For our measurements, it is important to note that the positive- and negative-ion beams were not momentum analyzed. Reported beam sizes include all ions (e.g., $\mathrm{C}$, $\mathrm{O}, \mathrm{CO}, \mathrm{O}_{2}, \mathrm{CO}_{2}$, etc.).

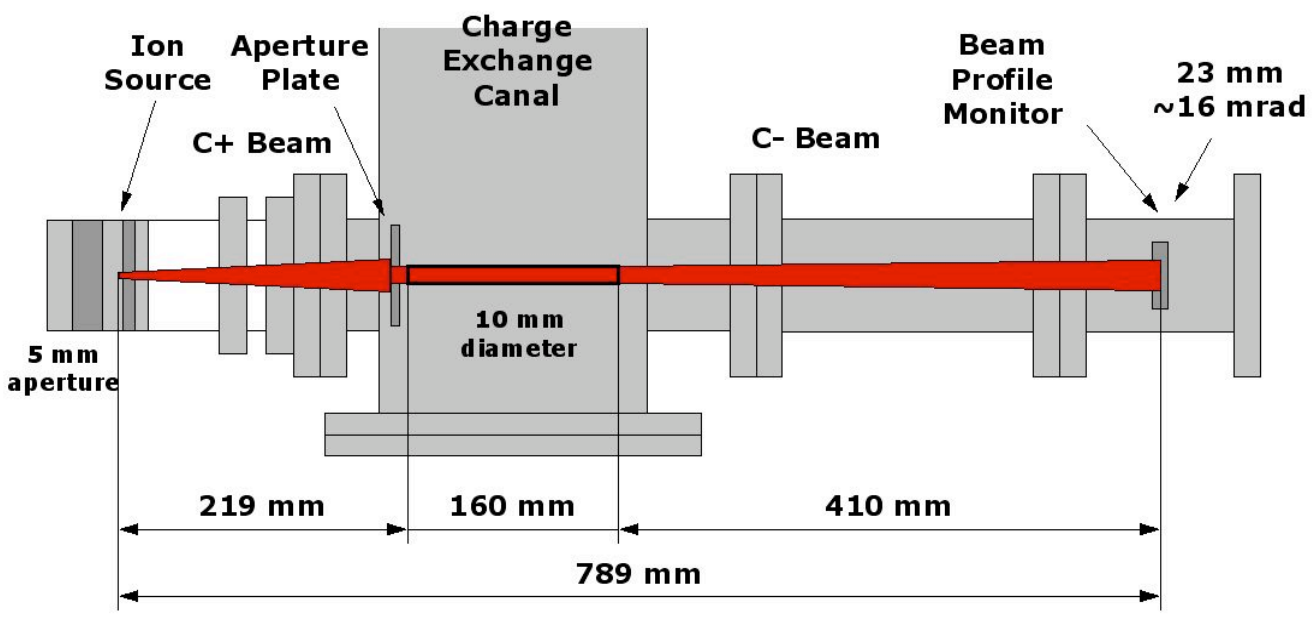

Figure 4. Schematic of the setup used to determine beam divergence and emittance. Beam emittance is approximately $80 \pi \cdot \mathrm{mm} \cdot \mathrm{mrad}$ at $30 \mathrm{keV}$. 
A magnesium charge-exchange canal was used to convert $\mathrm{C}^{+}$ions to $\mathrm{C}^{-}$ions. In our case, maximum momentum-analyzed $\mathrm{C}^{-}$currents were obtained at magnesium temperatures of about $490^{\circ}$ C. Unfortunately, a large energy spread was introduced into the beam during the chargeexchanging process. Calculations with SRIM $^{[10]}$ indicated an average energy loss of $325 \mathrm{eV}$ with an energy spread of $\pm 323 \mathrm{eV}$ at a nominal beam energy of $30 \mathrm{keV}$. Using the test stand magnet as an energy analyzer, this energy spread was also confirmed by experimental observations. To efficiently transport a beam with large energy spread, the associated AMS system will need to be energy-stigmatic (or achromatic) at the low-energy end.

To test the ion source for memory and stability effects, the gas ion source and chargeexchange canal were temporarily mounted in place of one of the standard sputter ion sources on the current AMS system. Unfortunately, the angular divergence and energy spread of the ion beam was large relative to that from the standard source. To avoid scattering of ions and charging of surfaces, a beam-limiting aperture of $5 \mathrm{~mm}$ diameter was installed at the object point of the injector system. Even with this limitation, $\mathrm{C}^{-}$beams as large as $22 \mu \mathrm{A}$ were obtained and the entrance to the accelerator. When pulses of $\mathrm{CO}_{2}$ produced by combustion of the Ox-I and Ox-II oxalic-acid standards were analyzed sequentially, the observed ratio of ${ }^{14} \mathrm{C} /{ }^{12} \mathrm{C}$ ratios was 1.27. Given the low total numbers of ${ }^{14} \mathrm{C}$ ions collected, this result does not differ significantly from the accepted value of 1.29. Figure 5 shows the response of the AMS system when alternating between a ${ }^{14} \mathrm{C}$ containing $\mathrm{CO}_{2}$ gas stream and 'dead' $\mathrm{CO}_{2}$ gas stream into the ion source. The absence of any appreciable retention time for ${ }^{14} \mathrm{C}$ is clearly evident.

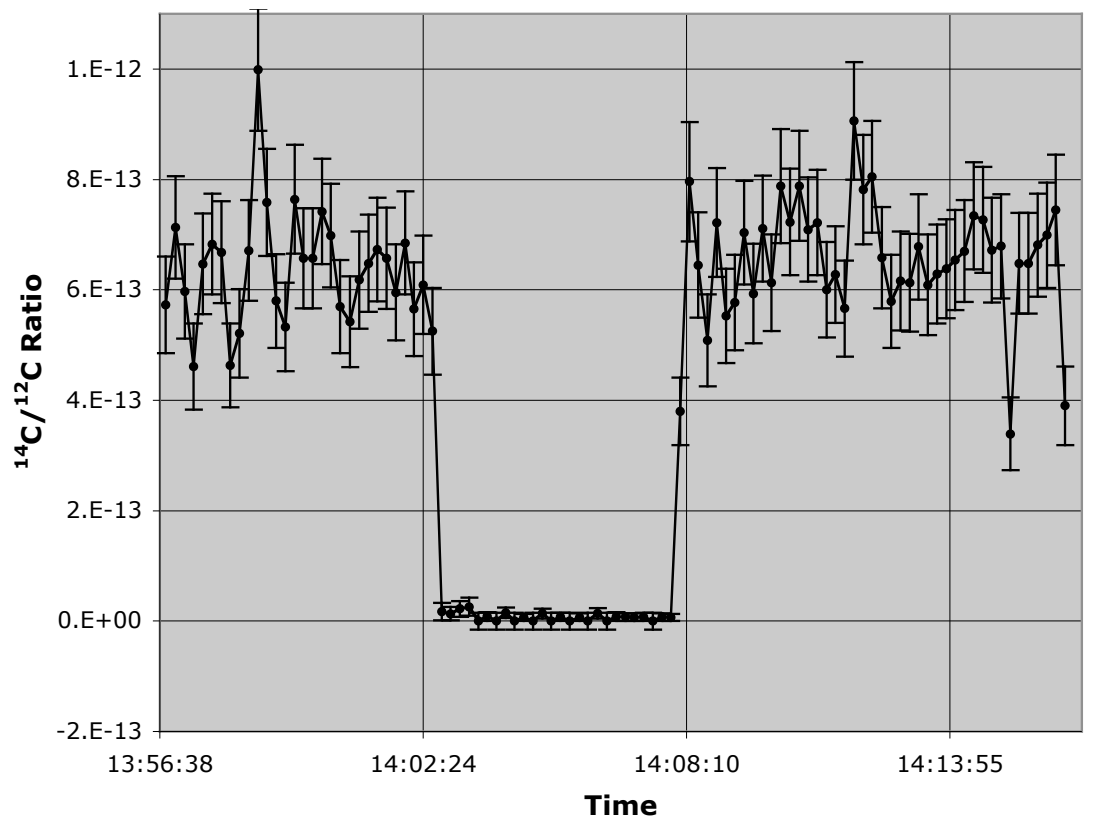

Figure 5. System response to alternating ${ }^{14} \mathrm{C}$-containing and 'dead' $\mathrm{CO}_{2}$ gas streams.

\section{Future Improvements}

In collaboration with Atomic Energy of Canada Limited, Chalk River, Ontario, Canada, we are presently designing an improved version of the ion source. A drawing of the new ion source is shown in Figure 6. Details of the extraction geometry and magnetic fields were optimized through the respective use of the software PBGUNS ${ }^{[11]}$ and Infolytica ${ }^{[12]}$ MagNet. In comparison to the current ion source, the new version has several improvements including: i) better coupling to the magnesium-vapor charge-exchange canal, ii) improved control of the magnetic field (by using a solenoid magnet rather than permanent magnets), iii) improved alignment capability, iv) the ability to operate at potentials higher than $30 \mathrm{kV}, \mathrm{v}$ ) the elimination 
of internal water seals with O-rings, and vi) the use of commercially available brazed insulators (as opposed to a glued ceramic/metal extraction column).

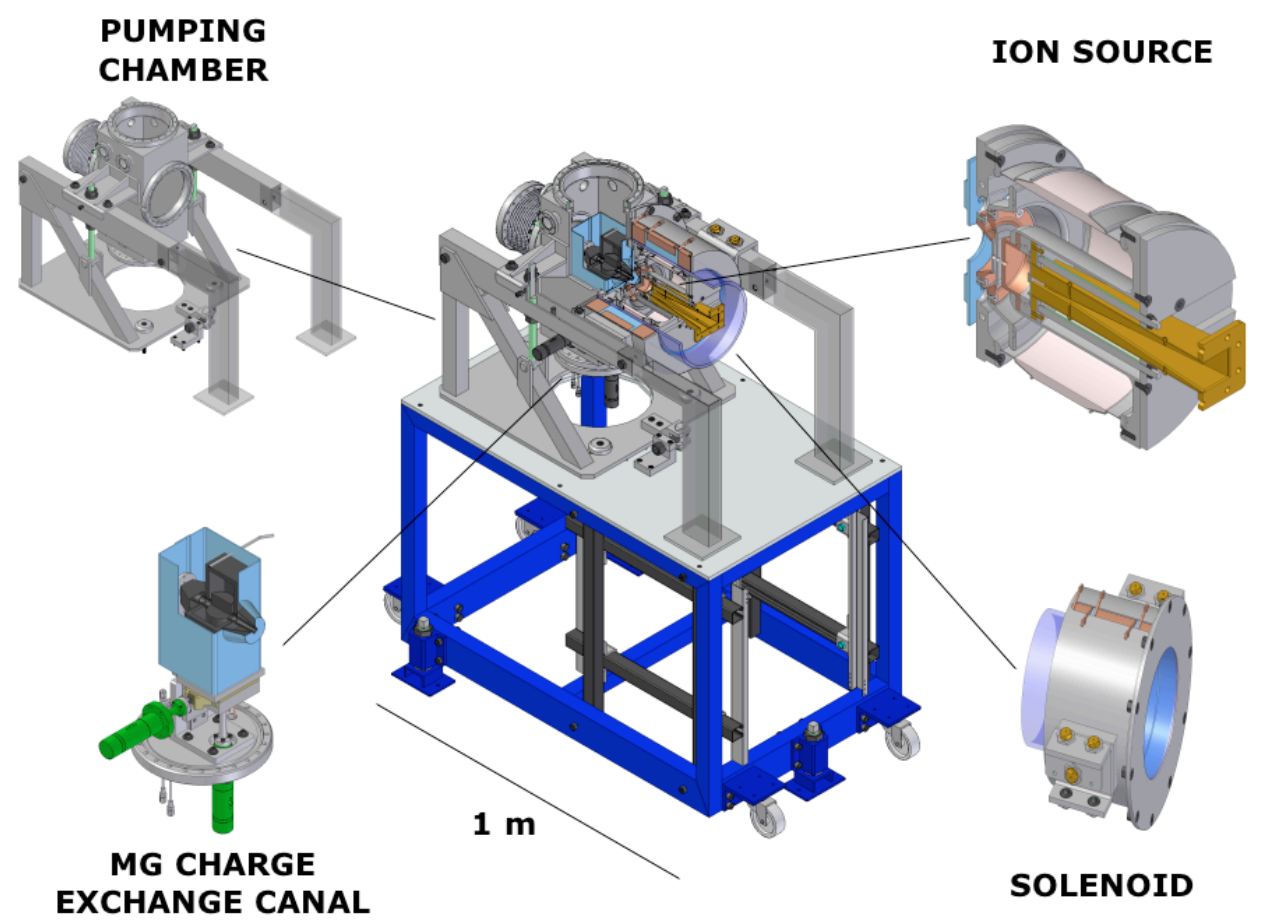

Figure 6. Drawing of the ion source being designed in collaboration with Chalk River Laboratories.

In addition to the listed operational improvements, the new ion source will also be designed so that the magnesium charge-exchange canal can be 'floated' to high voltage. The plan is to operate the charge-exchange canal at negative $30 \mathrm{kV}$ while maintaining the ion source at entrance to the low-energy spectrometer at ground potential. The resulting 'tandem' chargeexchange canal will yield ion beams with a total energy of $60 \mathrm{keV}$. This doubling of beam energy will reduce the relative energy spread by a factor of two and the beam emittance by $\sqrt{ } 2$.

\section{Sample Size Requirements}

A continuous-flow AMS system is practicable only if means are available for getting samples into a gas stream compatible with the gas-accepting ion source. It will not work if the sample processing devices (e.g., a gas chromatograph) deliver high flow rates of helium and $\mathrm{CO}_{2}$ while the AMS system requires low flow rates of $\mathrm{CO}_{2}$ and argon (argon will be used as a carrier gas to buffer $\mathrm{CO}_{2}$ flow to the ion source to maintain a constant overall flow rate). To address this issue, we must first estimate sample requirements. As stated above, the demonstrated efficiency of the ion source / charge-exchange canal for the conversion of $\mathrm{CO}_{2}$ ions to $\mathrm{C}^{-}$ions is $0.4 \%$. The AMS system should yield $50 \%$ of the incoming $\mathrm{C}^{-}$ions as $\mathrm{C}^{+}$ions at the detector. This gives an overall efficiency of $0.2 \%$ for collected ions per molecule of $\mathrm{CO}_{2}$ introduced.

In AMS measurements, we measure the ratio of ${ }^{14} \mathrm{C}$ ions collected to ${ }^{12} \mathrm{C}$ ions collected:

$$
R=\frac{{ }^{14} C}{{ }^{12} C}
$$

and the error in the ratio is given by: 


$$
\frac{\sigma_{R}}{R}=\sqrt{\frac{1}{14 n}+\frac{1}{12 n}} \approx \sqrt{\frac{1}{14 n}}
$$

where ${ }^{14} n$ and ${ }^{12} n$ are the number of ${ }^{14} \mathrm{C}$ and ${ }^{12} \mathrm{C}$ ions collected. To achieve a $10 \%$ statistical uncertainty $\left(\sigma_{R} / R=0.1\right)$ we need $100{ }^{14} \mathrm{C}$ ions. For a half-modern sample $\left(\mathrm{R} \approx 0.5 \times 10^{-12}\right)$ this requires $200 \times 10^{12}{ }^{12} \mathrm{C}$ ions. Using an overall efficiency of $0.2 \%$, this requires admission to the ion source of $1 \times 10^{17}$ molecules of $\mathrm{CO}_{2}$ or approximately $0.2 \mu \mathrm{mol}$ of $\mathrm{CO}_{2}(2 \mu \mathrm{g}$ of $\mathrm{C})$ be admitted to the ion source.

\section{Summary}

A gas-accepting ion source suitable for continuous-flow Accelerator Mass Spectrometry has been characterized. The ion source charge-exchange canal combination produces reasonable ion currents with low memory. Unfortunately, the combination also produces a beam with large emittance and large energy spread. To avoid excessive transmission losses, the AMS system to which this source will be connected will need to have large-gap optical elements and a lowenergy, energy-stigmatic transport system (or achromat). An ion optical modeling of an AMS system with these characteristics is described elsewhere in these proceedings ${ }^{[13]}$.

\section{References}

[1] Pearson A., McNichol A.P., Benitez-Nelson B.C., Hayes J.M., and Eglinton T.I. (2001) Origins of lipid biomarkers in Santa Monica Basin surface sediment: A case study using compound-specific $\Delta 14 \mathrm{C}$ analysis. Geochim. Cosmochim. Acta 65, 3123-3137.

[2] Reddy C.M., Eglinton T.I., Hounshell A., White H.K., Xu L., Gaines R.B., and Frysinger G.S. (2002) The West Falmouth oil spill after thirty years: The persistence of petroleum hydrocarbons in marsh sediments. Environ. Sci. Technol. 36, 4754-4760.

[3] Wills J.S.C., Lewis R.A., Diserens J., Schmeing H. and Taylor T. (1998) A compact high-current microwavedriven ion source. Rev. Sci. Instrum. 69, 65-68.

[4] Schneider R.J., von Reden K.F., Wills J.S.C., Diamond W.T., Lewis R., Savard G., and Schmeing H. (1997) Hold-up and memory effect for carbon in a compact microwave ion source. Nucl. Instr. and Meth. in Phys. Res. B 123, 546-549.

[5] Schneider R.J., Hayes J.M., von Reden K.F., McNichol A.P., Eglinton T.I., and Wills J.S.C. (1998) Target preparation for continuous flow accelerator mass spectrometry. Radiocarbon 40, 95-102.

[6] Schneider R.J., von Reden K.F., Hayes J.M., Wills J.S.C, Kern W.G.E, and Kim S.-W. (2000) Tests of positive ion beams from a microwave ion source for AMS. Nucl. Instr. and Meth. in Phys. Res. B 172, 252256.

[7] Kim S.-W, Schneider R.J., von Reden K.F., Hayes J.M., and Wills J.S.C, (2002) Tests of negative ion beams from a microwave ion source with a charge exchange canal for accelerator mass spectrometry applications. Rev. Sci. Instrum. 73-2, 846-848.

[8] Norton G.A. (2003) National Electrostatics Corporation, Middletown, WI, personal communication.

[9] Southon J.R. and Roberts M.L. (2000) Ten years of sourcery at CAMS/LLNL - Evolution of a Cs ion source. Nucl. Instr. and Meth. in Phys. Res. B 172, 257-261.

[10] Ziegler, J.F., Biersack J.P., and Littmark, U. (2003) The Stopping and Range of Ions in Solids, Pergamon Press, New York.

[11] Welton R.F., Stockli M.P., Boers J.E., Rauniyar R., Keller R., Staples J.W., and Thomae R.W. (2002) Simulation of the ion source extraction and low energy beam transport systems for the Spallation Neutron Source. Review of Scientific Instruments 73, 1013- 1016.

[12] Infolytica Corporation, Montreal, Quebec, Canada.

[13] Han, B.X., von Reden K.F., Roberts, M.L., Schneider R.J., and Hayes J.M., (2002) 3-D Electromagnetic Field Modeling and Ion Optics Calculations for a Continuous-Flow AMS System. These proceedings. 